\title{
Spatial distribution of display sites of Grey Peacock-pheasant in relation to micro-habitat and predators during the breeding season
}

\author{
Somying Thunhikorn ${ }^{1 *}$, Matthew J. Grainger ${ }^{2}$, Philip J. K. McGowan ${ }^{2 \dagger}$ and Tommaso Savini ${ }^{1 \dagger}$
}

\begin{abstract}
Background: The destruction and fragmentation of forest in Southeast Asia is accelerating biodiversity loss, resulting in a range of management and conservation actions. For some species, a detailed understanding of microhabitat selection is critical for this, especially in the breeding season.

Methods: To understand the factors that explain how specific habitats are used by the Grey Peacock-pheasant (Polyplectron bicalcaratum) in the breeding season, we used camera trapping and microhabitat sampling to assess the microhabitat selection of males. We also looked at their interaction with predators in an area of $1200 \mathrm{~m} \times 1200 \mathrm{~m}$ at the Huai Kha Khaeng Wildlife Sanctuary, Thailand, between January and May 2013.

Results: We show that display scrapes are situated on flatter open areas with small saplings and some vines, typified by low horizontal understory density. We hypothesise that this allows a trade-off between courtship display and the avoidance of predators. Our study showed that the position of Grey Peacock-pheasant display scrapes regularly overlapped with predators within the same microhabitat. We hypothesise that the species' behavioural responses to temporal variation in predation risk allows them to avoid most predators.
\end{abstract}

Conclusions: Particular microhabitats are required for Grey Peacock-pheasant display. They avoid predators at these places by being active when predators are not.

Keywords: Huai Kha Khaeng Wildlife Sanctuary, Display scrape, Species accumulation, Predator-prey, Polyplectron bicalcaratum

\section{Background}

Tropical rainforest cover in Southeast Asia decreased by an estimated 14.5\% between 1995 and 2010 (Miettinen et al. 2011) with rates of loss predicted to continue at ca. $1 \%$ per year (Laurance 1999; Achard et al. 2002). This massive and rapid habitat change is having serious effects on the richness and abundance of forest-dependent taxa (Sodhi et al. 2010; Gillespie et al. 2015). We know little

\footnotetext{
*Correspondence: somyingphuluang@hotmail.com

${ }^{\dagger}$ Philip J. K. McGowan and Tommaso Savini contributed equally to this work

${ }^{1}$ Conservation Ecology Program, School of Bioresources and Technology, King Mongkut's University of Technology Thonburi, 49 Soi Thian Thale 25, Bang Khun Thian Chai Thale Road, Tha Kham, Bang Khun Thian, Bangkok 10150, Thailand

Full list of author information is available at the end of the article
}

about the ecological or behavioural impacts on many species however, because basic ecological knowledge about many species in the region is seriously lacking. For example, little is known about the processes that shape spatial distribution of courtship display sites of individuals within Southeast Asian forest. Although it has been suggested that ecological resources and conspecifics play crucial roles in shaping male and female display distribution (Brown and Orians 1970), information on spatial patterns remains scarce for many animal groups and, therefore, understanding what might drive observed display site distribution in degrading habitat is far from clear.

Solitary breeding males of some bird species display at or around fixed points during the breeding period and this makes them conspicuous and, therefore, more 
detectable, than is the case with other species. This includes species in this region such as the Malaysian Peacock-pheasant (Polyplectron malacense) (McGowan 1994) and Great Argus (Argusianus argus) (Davison 1981).

Knowledge of spatial patterns and the factors driving them remain incomplete and there appears to have been little research in this area over the last two decades. The development of technological and analytical approaches now provides the opportunity to both gather new data and to obtain greater ecological insights from those data. For example, knowledge of the identities of other species that occur at such fixed display areas allows more robust assessment of animal communities and thus is important in understanding ecological patterns in an area (Nichols et al. 1998). Documenting the occurrence of predators and understanding predation risk for conspicuous displaying males would be a signficant step towards this.

Information on the spatial distribution of male display sites and its drivers may well have importance in ensuring that predictions of consequences for species of anthropogenic change are more realistic than would otherwise be the case (Fletcher et al. 2012). At a time when loss and disruption of habitat is increasing, and particular species are targeted for hunting, this information could be very timely in allowing us to understand the wider consequences of such change. For example, loss of specific microhabitats may prevent males from exhibiting appropriate display behaviour, e.g. the Black Grouse (Lyrurus tetrix) (Patthey et al. 2012) and the Lesser Prairie-chicken (Tympanuchus pallidicinctus) (Larsson et al. 2013). Furthermore, knowledge of the relationship between microhabitat use and predation risk may allow insights into variation in survival (DeCesare et al. 2014).

The Grey Peacock-pheasant is a sedentary and loud calling ground-dwelling bird that inhabits dense forest over hilly terrain (Johnsgard 1999). Males create and maintain a particular area for display and courtship behaviour, similar to that described for the Great Argus (Davison 1981) and the Malaysian Peacock-pheasant (Davison 1983a). These display scrapes are small patches of the forest floor from which all fallen leaves and vegetation are removed, so that bare earth is exposed. Males are thought to call mainly from these display scrapes during the breeding season (Baker 1930) and calls have been interpreted as a challenge call to other males and an attraction call to females (Johnsgard 1999). Grey Peacock-pheasant's global conservation status is Least Concern (IUCN 2017), although Grey Peacock- pheasant's population trend is decreasing (IUCN 2017), recent analysis of their available habitat is only $16 \%$ (Savini $\mathrm{T}$ unpublished data) of that reported by IUCN Red List of Threatened Species (IUCN 2017), and also in Thailand, it is classified as protected wildlife under the Wildlife Preservation and Protection Act of 1992 (Wildlife Preservation and Protection Act 1992). This suggests that the status of the species is especially of concern in its Southeast Asian range, probably as a result of widespread habitat loss and fragmentation, combined with indiscriminate widespread illegal hunting. Here we: (1) describe the spatial distribution of Grey Peacock-pheasant, (2) assess the microhabitat use of Grey Peacock-pheasant, (3) assess the occurrence of ground-dwelling bird and mammal species at display scrapes and elsewhere in the study area, and (4) ask if Grey Peacock-pheasant display scrapes were sited in areas with relatively few potential predators.

\section{Methods}

\section{Study site}

This study was conducted at Huai Kha Khaeng Wildlife Sanctuary $\left(15^{\circ} 00^{\prime}-15^{\circ} 48 \mathrm{~N}, 98^{\circ} 89^{\prime}-99^{\circ} 27^{\prime} \mathrm{E}\right.$, Fig. 1), which was declared a protected area in 1972. It covers an area of $2780 \mathrm{~km}^{2}$ at the eastern edge of the Western Forest Complex in Western Thailand. It is part of the Thanon Thong Chai Mountain Complex that lies in the Tenasserim Range along the Thailand-Myanmar border. Our study site covers $1200 \mathrm{~m} \times 1200 \mathrm{~m}$ of rugged ridges and narrow valleys at $700-1500 \mathrm{~m}$ in hill evergreen and dry evergreen forest, near the Khao Nang Rum Research Station in the south-eastern part of the sanctuary. The study site has three seasons: the wet season (May to October) with the temperature ranging between 6 and $38{ }^{\circ} \mathrm{C}$, the dry season (November to April) when the temperature ranges between 10 and $29{ }^{\circ} \mathrm{C}$, and during this dry season, there is a short cold and dry winter (December and January). The average annual rainfall is $1552 \mathrm{~mm}$ with the maximum rainfall in October $(370 \mathrm{~mm}$ ) (National Parks Wildlife and Plant Conservation Department 2014).

\section{Field methods}

We assessed the microhabitat selection of Grey Peacock-pheasant by comparing the topography, vegetation structure, and food availability between: (1) used locations versus available locations, (2) display scrapes versus available locations, and (3) used locations versus display scrapes during the breeding season. Display scrapes are the areas cleared by breeding males where they vocalize and display. Camera traps were also used to compare animal species composition between display scrapes and random camera trap locations in the study site, and to assess whether there was a co-occurrence between highest ranking potential predators and Grey Peacock-pheasant at those sites. Fieldwork was conducted during the 2013 breeding season (January-May).

We identified 'used' and 'available' locations of Grey Peacock-pheasant in the breeding season at 


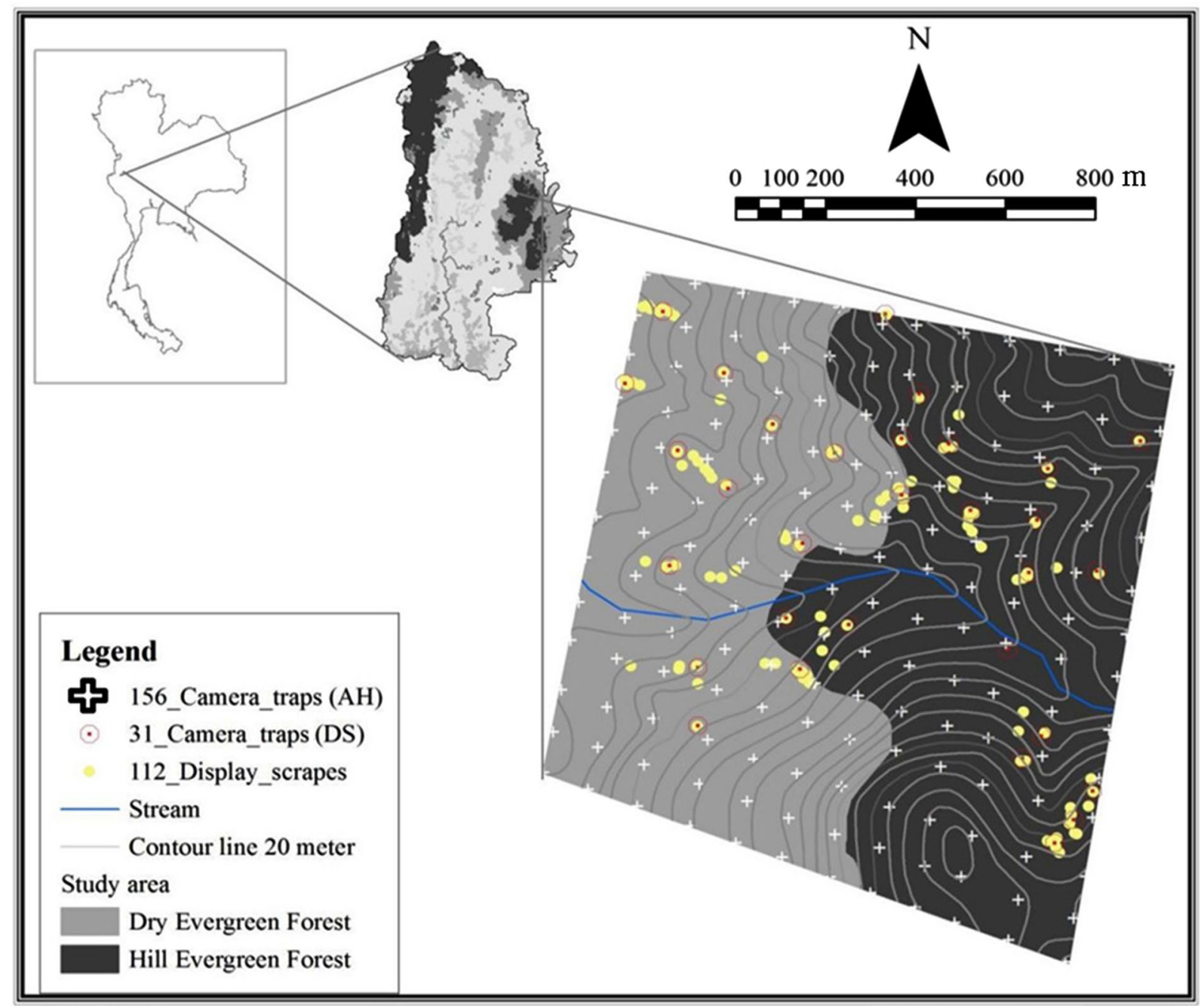

Fig. 1 Location of 156 camera trap sampling and display scrape searching in 1200 m × 1200 m at Huai Kha Khaeng Wildlife Sanctuary, Uthai Thani, Thailand

156 camera trap locations throughout the study area over a $100 \mathrm{~m} \times 100 \mathrm{~m}$ grid covering a total area of $1200 \mathrm{~m} \times 1200 \mathrm{~m}$. A Geographic Information System (ESRI 2008) was used to generate a $100 \mathrm{~m}^{2}$ grid that was overlaid on a map of the study area $\left(1.44 \mathrm{~km}^{2}\right)$. Then, for used locations, the camera trap locations were used to produce a further 156 locations, 48 of which were used by the species; for available locations, the centroid of each $100 \mathrm{~m} \times 100 \mathrm{~m}$ grid was located to produce 132 locations across all available microhabitats.

We set up 156 camera trap locations across the study area as follows, a total of 39 camera traps were set $100 \mathrm{~m}$ apart in three parallel lines running north-south (13 cameras per line) $400 \mathrm{~m}$ apart for 30 consecutive days. They were then shifted $100 \mathrm{~m}$ eastwards for the following 30 days and so on. The entire study area was, therefore, covered in four blocks between January and May 2013 (Fig. 1). We used Scout Guard, SG565F-8M, a digital scouting camera with an incandescent flash that can be triggered by any movement in front of a passive infrared sensor. The camera traps were programmed to record video $24 \mathrm{~h}$ per day in camera mode (depending upon light availability) with three pictures/trigger and a time delay for activation of one second apart. Each video or photograph was date and time stamped. Camera traps were attached to a suitable tree at a height of $40-50 \mathrm{~cm}$ above the ground and with an angle of depression of $5-10^{\circ}$.

We searched intensively for display scrapes throughout the study area between January and the end of April 2013. We did this by dividing the study site into six subplots of $400 \mathrm{~m} \times 600 \mathrm{~m}$. Four observers searched each subplot and were spread $100 \mathrm{~m}$ apart to ensure even search effort 
across each subplot. The size of all display scrapes was measured (width $\times$ length) and its position recorded on the Universal Transverse Mercator coordinate system $(X$, $Y$ ). We checked to see if each display scrape was used in the following (year 2014) breeding season.

We measured microhabitat variables in circular plots that were centred on the 48 used locations, 112 display scrapes and 132 available locations across the study area. For each plot 12 variables were recorded. Within each $10 \mathrm{~m}$ radius we recorded the number and diameter at breast height $(\mathrm{DBH})$ of trees $(\mathrm{DBH} \geq 4.5 \mathrm{~cm})$, number of vines, and horizontal understory density. Within each $5 \mathrm{~m}$ radius, we recorded the number of saplings $(\mathrm{DBH} \leq 4.5 \mathrm{~cm}$, height $>1.30 \mathrm{~m})$ and within each $1 \mathrm{~m}$ radius, we recorded the number of seedlings (height $<1.30 \mathrm{~m}$.), number of soil invertebrates (i.e. insects, worms), and number of fallen fruits. In addition, at each plot we also measured canopy cover, slope, aspect and elevation. These habitat characteristics reflect the openness of the habitat (and conversely the availability of cover), the availability of food (Grey Peacock-pheasants feed on both insects and fruit) and the characteristics of the site that might promote calling by males (e.g. slope of the site, elevation and canopy cover).

We assessed animal species occurrence at display scrapes between February and May 2013 by setting one to three camera traps at each display scrape, depending on the size of display scrape and the amount of vegetation cover. Multiple detections from one scrape at the same time were treated as a single detection. In some cases there were several display scrapes in a cluster and so cameras were set so as to maximize the likelihood of capturing individuals present given the configuration of the scrapes. Overall, camera traps were set at 31 display scrapes between 20 and 45 days (Fig. 1).

\section{Data analysis}

Microhabitat variables measured at used locations, available locations and display scrapes were compared using an independent Mann-Whitney $U$ test for non-normally distributed data. Variables that differed significantly $(p<0.05)$ were retained for analysis as reduced and fitted variables in General Linear Models (GLMs). We tested for multicollinearity among independent variables using Pearson's correlation matrix and we did not allow independent variables with high correlation coefficients $(|r| \geq 0.70)$ in the same model. We standardised the value of each variable with a $z$-score transformation, so that each variable has mean of 0 and standard deviation of 1 (Knopff et al. 2014).

This produced a list of 12 variables. We then created a model in R 3.2.1. (R Core Team 2015) that combines variables as efficiently as possible to explain the microhabitat selection difference between: (1) used locations and available locations, (2) display scrapes and available locations, and (3) display scrapes and used locations. We did this in three steps as follows.

Step 1: We conducted binary logistic regression modelling utilising a binomial GLM and then used the information theoretic approach based on Akaike's Information Criteria (AIC), Akaike difference ( $\triangle \mathrm{AIC})$ and Akaike weight $\left(w_{i}\right)$ (Burnham and Anderson 2002) to select candidate models, which had $\triangle \mathrm{AIC}$ between 0 and 2, indicating that there is strong support for the model (Burnham and Anderson 2002). This indicates that the candidate model explains much of the variation in microhabitat selection of used locations and display scrapes.

Step 2: We looked at how much of the variation in the pattern was explained by the candidate models and identified the top model, which was the one that explained most variation in the microhabitat at the two types of sites where Grey Peacock-pheasants were recorded (i.e. used location, display scrapes). We used the package AICcmodavg 2.3-2 to calculate the Akaike model weights for all candidate models (Mazerolle 2015). For the top model the Akaike model weight was less than 0.90, indicating that it was not the single best model in the set (Burnham and Anderson 2002) and so we used model averaging for the final model selection.

Step 3: We then interpreted the average model in terms of microhabitat variables. We performed model averaging for microhabitat selection at used locations and display scrapes. The Hosmer-Lemeshow test was used to test for model fit and we used package pROC R package version 1.8 (Robin et al. 2015) to calculate for the area under the Receiver Operator Curve (ROC) to measure the accuracy of model.

We compared the species composition of the large vertebrate assemblage at display scrapes with that in available habitat across the study site by identifying photographs from camera traps. Photographs that were not clear enough to permit identification to species level were excluded from our analysis. Photographs had to be taken more than $1 \mathrm{~h}$ apart to be considered independent events, so as to avoid double counting of individual animals lingering in front of the camera (Mugerwa et al. 2012). We used the camera trapping rate as an index of abundance. Camera trapping rate was defined as the ratio of independent photographs of each species to the number of trap days (number of $24 \mathrm{~h}$ periods that the cameras were deployed) and multiplied by 100 . We then used the mean trapping rate as a measure of the Relative Abundance Index (RAI) of each species across the study area following (Rovero and Marshall 2009). We used tools inside the community ecology package (Vegan) R package 
version 2.3-2 (Oksanen et al. 2015) for describing the animal community at display scrapes and at other camera trap locations by using: (1) Species Accumulation Curve (Specaccum) to compare animal species richness between display scrapes and random camera trap locations, (2) Non-metric Multidimensional Scaling (NMDS) for measuring animal community (species and abundance) dissimilarities between display scrapes and random camera trap locations, (3) Analysis of Similarities (ANOSIM) to test statistically whether there was among group difference in species and abundance between display scrapes and random camera trap locations, and (4) Similarity Percentages (SIMPER) for discriminating animal community between display scrapes and random camera trap locations by using Bray-Curtis dissimilarities.

We assessed whether there was a co-occurrence between the most commonly detected potential predators and Grey Peacock-pheasant at the display scrapes in four steps, as follows:

Step 1: We determined potential predators based on our knowledge of predator feeding and hunting behaviour, including the overlapping activity periods of Grey Peacock-pheasant and predators in an area (Fig. 4).

Step 2: Photographs of these potential predators were pooled into two groups according to where they were taken, 'display scrape' or 'random camera trap locations'.

Step 3: We considered the frequency of camera trapping of potential predators to determine the most commonly photographed potential predators for analysis of co-occurrence of predators and Grey Peacock-pheasant.

Step 4: The co-occurrence of the potential predators and Grey Peacock-pheasant was interpreted in terms of occupancy and detection of both (i.e. peacock-pheasants and predators) at display scrapes following (Richmond et al. 2010; Magle et al. 2014) by using two species single season interaction in Presence Program 6.1 (Mackenzie et al. 2004; Donovan and Hines 2007).

\section{Results \\ Dispersion of Grey Peacock-pheasant Display scrapes}

We found 112 display scrapes (Fig. 1) with a mean size of $0.57 \pm 0.018$ (SE) $\mathrm{m} \times 0.90 \pm 0.037 \mathrm{~m}$. Each male created and maintained more than one display scrape (mean $=3.92 \pm 0.52, n=27$ individuals) and these were aggregated into clusters. The mean distance between display scrapes in a cluster was $35.26 \pm 3.66 \mathrm{~m}(n=77$ clusters), $95 \% \mathrm{CI}$ and the mean diameter of a cluster of scrapes was $106.3 \pm 14.40 \mathrm{~m}(95 \%$ CI $(80,135))$. Display scrapes were maintained in the same general area in both years and $20.72 \%$ of individual scrapes used in 2013 were reused in the following breeding season (2014).

\section{Used locations}

Grey Peacock-pheasant was detected at 48 locations of the 156 where camera traps were set between January and May 2013.

\section{Microhabitat selection Microhabitat characteristics}

The microhabitat of the used locations showed some differences from the available locations. Mann-Whitney $U$ test showed that six of 12 independent variables were significantly different and lower than in the available locations with tree basal area, density of saplings, density of fruits (Mann-Whitney $U$ test $p<0.001$, Table 1 ) and slope, percent of tree canopy, density of insects (MannWhitney $U$ test $p<0.05$, Table 1 ).

Nine microhabitat characteristics differed significantly between display scrapes and available locations. Display scrapes were sited in areas that were significantly flatter, with open canopy, lower horizontal understory density, smaller trees at higher density, higher density of vines, higher density of saplings, lower density of insects and fallen fruits (Mann-Whitney $U$ test, $p<0.001, p<0.05$, Table 1).

The microhabitat at display scrapes differed from used locations, with eight of the 12 variables differing significantly between the two: slope (less than at used locations), percent of horizontal understory density (less than used locations), density of trees (higher than used locations), density of fruit on the ground (higher than used locations) (Mann-Whitney $U$ test, $p<0.001$ ). Most display scrapes were facing west whereas used locations were facing southwest, elevation was lower than in the used locations, density of saplings was higher than in the used locations and density of insects was lower than in the used locations (all Mann-Whitney $U$ test $p<0.05$ Table 1).

\section{Microhabitat selection at used locations of Grey Peacock-pheasant in breeding season}

Seven microhabitat selection models were considered as candidate models for the used locations as they showed a $\triangle \mathrm{AIC}_{\mathrm{c}}<2$ and low model support weight variation $\left(w_{i}\right.$ between 0.23 and 0.09 , see Table 2 for details). The microhabitat independent variables highlighted by those seven models are tree basal area, slope, percent of tree canopy closure, elevation, horizontal understory density, density of saplings, density of insects, density of fruits, density of trees and aspect (Table 2). Averaging the seven candidate models in the final microhabitat selection model for used location resulted in a negative trend with the basal area 
Table 1 Comparison of habitat variable measured on Grey Peacock-pheasant used locations ( $n=48$ locations), display scrapes ( $n=112$ locations), and available location ( $n=132$ locations)

\begin{tabular}{|c|c|c|c|c|c|c|c|}
\hline \multirow[t]{2}{*}{ Variable } & \multirow[t]{2}{*}{ Variable description } & \multicolumn{3}{|l|}{ Median } & \multicolumn{3}{|c|}{ Mann $U$ test } \\
\hline & & Used location & Display scrape & $\begin{array}{l}\text { Available } \\
\text { location }\end{array}$ & $1^{\mathrm{a}}$ & $2^{b}$ & $3^{c}$ \\
\hline Slp & Slope $\left(^{\circ}\right)$ & 21.50 & 15 & 24.00 & 0.003 & $<0.001$ & 0.001 \\
\hline Asp & Aspect $\left(^{\circ}\right)$ & 248 & 265 & 270 & 0.15 & 0.40 & 0.05 \\
\hline Ele & Elevation (m) & 906.50 & 852 & 879 & 0.23 & 0.18 & 0.03 \\
\hline TreeCCS & Tree canopy closure (\%) & 91.50 & 91 & 93 & 0.02 & 0.03 & 0.96 \\
\hline VertD & Vertical dense (\%) & 76 & 28.50 & 72.00 & 0.09 & $<0.001$ & $<0.001$ \\
\hline $\mathrm{BA}$ & Tree basal area $\left(\mathrm{m}^{2}\right)$ & 0.77 & 0.77 & 2.45 & $<0.001$ & $<0.001$ & 0.49 \\
\hline DENTR & $\begin{array}{l}\left.\text { Density of trees (number of trees } / \mathrm{m}^{2}\right)(\mathrm{DBH} \geq 4.5 \mathrm{~cm} \text {, } \\
\text { height }>1.30 \mathrm{~m})\end{array}$ & 0.08 & 0.10 & 0.08 & 0.81 & $<0.001$ & $<0.001$ \\
\hline DENSPL & $\begin{array}{l}\left.\text { Density of sapling (number of saplings } / \mathrm{m}^{2}\right)(\mathrm{DBH} \leq 4.5 \mathrm{~cm} \text {, } \\
\text { height }>1.30 \mathrm{~m})\end{array}$ & 0.23 & 0.27 & 0.23 & $<0.001$ & 0.002 & 0.02 \\
\hline DENSDL & Density of seedlings (number of seedlings $/ \mathrm{m}^{2}$ ) (height $<1.30 \mathrm{~m}$ ) & 3.02 & 3.18 & 3.18 & 0.63 & 0.75 & 0.69 \\
\hline DENVI & Density of vines (number of vines $/ \mathrm{m}^{2}$ ) & 0.008 & 0.01 & 0.006 & 0.06 & $<0.001$ & 0.07 \\
\hline DENINS & Density of insects (number of insects $/ \mathrm{m}^{2}$ ) & 10.03 & 6.37 & 13.69 & 0.005 & $<0.001$ & 0.04 \\
\hline DENFRU & Density of fruits (number of fruits $/ \mathrm{m}^{2}$ ) & 3.66 & 15.92 & 25.80 & $<0.001$ & 0.03 & $<0.001$ \\
\hline
\end{tabular}

$1^{\mathrm{a}}: p$ value between used locations versus available locations

$2^{\mathrm{b}}: p$ value between display scrape locations versus available locations

$3^{c}: p$ value between used locations versus scrape locations of Grey Peacock-pheasant

Table 2 Ranking microhabitat candidate model for used location in breeding season and display scrape location scrape

\begin{tabular}{|c|c|c|c|c|c|c|}
\hline Model & $K$ & $\mathrm{AIC}_{\mathrm{c}}$ & $\Delta \mathrm{AIC}_{\mathrm{c}}$ & $w_{i}$ & $\mathrm{LL}$ & ROC \\
\hline \multicolumn{7}{|l|}{ Used candidate model } \\
\hline $\mathrm{BA}+\mathrm{SI} p+$ TreeCCS + Ele & 5 & 145.92 & 0 & 0.23 & -67.79 & 0.8887 \\
\hline $\mathrm{BA}+\mathrm{Slp}+$ TreeCCS + Ele + VertD & 6 & 146.28 & 0.36 & 0.20 & -66.90 & 0.8919 \\
\hline $\mathrm{BA}+\mathrm{Slp}+$ TreeCCS + Ele + DENSPL & 6 & 146.83 & 0.91 & 0.15 & -67.17 & 0.8892 \\
\hline $\mathrm{BA}+\mathrm{Slp}+$ TreeCCS +Ele + DENINS & 6 & 147.20 & 1.28 & 0.12 & -67.36 & 0.8867 \\
\hline $\mathrm{BA}+\mathrm{Slp}+$ TreeCCS + Ele + DENFRU & 6 & 147.40 & 1.48 & 0.11 & -67.46 & 0.8928 \\
\hline $\mathrm{BA}+\mathrm{Slp}+$ TreeCCS +Ele + DENTR & 6 & 147.63 & 1.71 & 0.10 & -67.57 & 0.8886 \\
\hline $\mathrm{BA}+\mathrm{Slp}+$ TreeCCS$+\mathrm{Ele}+\mathrm{Asp}$ & 6 & 147.93 & 2.0 & 0.09 & -67.72 & 0.8810 \\
\hline Null.model & 1 & 210.80 & & & & \\
\hline \multicolumn{7}{|l|}{ Display scrape candidate model } \\
\hline VertD + SIp + BA+DENINS & 5 & 85.43 & 0 & 0.55 & -37.59 & 0.9855 \\
\hline VertD + SIp + BA+DENSPL & 5 & 85.86 & 0.43 & 0.45 & -37.80 & 0.9851 \\
\hline VertD+SIp+BA+TreeCCS & 5 & 87.99 & 2.55 & & -37.87 & 0.9848 \\
\hline Null.model & 1 & 338.60 & & & & \\
\hline
\end{tabular}

Based on $K=$ number of model parameter, Akaike's information criterion $\left(\mathrm{AIC}_{\mathrm{c}}\right), \triangle \mathrm{AIC} \mathrm{C}_{\mathrm{c}}=\mathrm{AIC}$ for a given model minus AIC for the top model. $w_{i}=$ Akaike model weight, and $\mathrm{LL}$ is the log-likelihood. Competitive model $\left(\triangle \mathrm{AIC} \mathrm{C}_{\mathrm{c}}<2\right), \mathrm{ROC}=$ Receiver operating curve to indicating the true positive

of tree $(p<0.001)$, slope $(p=0.006)$, and a positive trend with percent of tree canopy closure $(p=0.021)$, elevation $(p=0.038)$, while horizontal understory density, density of saplings, density of insects, density of fruits, density of trees and aspect were not important $(p=0.189$, $0.257,0.365,0.471,0.705,0.715$, respectively) (see Table 3 for details; Hosmer-Lemeshow test, $\lambda^{2}=10.68, \mathrm{df}=8$, $p=0.22$ ).

\section{Microhabitat selection at display scrapes of Grey Peacock-pheasant}

Two models were considered as candidate models for explaining the microhabitat at display scrapes, as they showed a $\Delta \mathrm{AIC}_{\mathrm{c}}<2$ and low model support weight variation ( $w_{i}$ between 0.55 and 0.45 , see Table 2 for details). The independent microhabitat variables highlighted by those two models were horizontal understory density, 
Table 3 Results from averaging model fitted to model selection for used location in breeding season and display scrape of Grey Peacock-pheasant

\begin{tabular}{lrrrr}
\hline Variable & Coefficient & $\mathbf{9 5 \%}$ Cl & \multirow{2}{*}{$\boldsymbol{p}$ value } \\
\cline { 3 - 4 } & & Lower & Upper & \\
\hline Used model selection & & & & \\
Intercept & -2.789 & -3.803 & -1.775 & $<0.001$ \\
Basal area of tree & -5.177 & -7.311 & -3.043 & $<0.001$ \\
Slope & -0.676 & -1.156 & -0.195 & 0.006 \\
Tree canopy closure (\%) & 0.724 & 0.136 & 1.311 & 0.021 \\
Elevation & 0.496 & 0.038 & 0.954 & 0.038 \\
Horizontal understory & 0.071 & -0.387 & 0.530 & 0.189 \\
$\quad$ density & & & & \\
Density of saplings & 0.048 & -0.511 & 0.608 & 0.257 \\
Density of insects & -0.026 & -0.497 & 0.445 & 0.365 \\
Density of fruits & -0.035 & -0.911 & 0.840 & 0.471 \\
Density of trees & -0.022 & -1.167 & 1.123 & 0.705 \\
Aspect & 0.009 & -0.541 & 0.560 & 0.715 \\
Display scrape model selection & & & & \\
Intercept & -0.611 & -1.270 & 0.047 & 0.08 \\
Horizontal understory & -3.852 & -5.124 & -2.580 & $<0.001$ \\
$\quad$ density & & & & \\
Slope & -1.759 & -2.542 & -0.977 & $<0.001$ \\
Basal area of tree & -1.904 & -3.198 & -0.611 & 0.003 \\
Density of insects & -0.910 & -1.527 & -0.248 & 0.009 \\
Density of saplings & 0.400 & -1.040 & 1.840 & 0.016 \\
\hline & & & &
\end{tabular}

slope, tree basal area, density of insect, density of sapling (Table 2).

Averaging the two candidate models, the final microhabitat selection model of display scrape gave a significant negative effect $(p<0.001)$ with slope and horizontal understory density; a significant negative effect $(p<0.01)$ with tree basal area and density of insect; and a significant positive effect $(p<0.05)$ with density of sapling (see Table 3 for details; Hosmer-lemeshow test, $\lambda^{2}=1.48$, $\mathrm{df}=8, p=0.9929$ ).

\section{Occurrence of animal species}

A total of 2853 photographs were taken during 1266 trap days at 31 display scrapes, which gives a mean camera trap rate of 40.83 days/location. There were 333 photographs that were excluded either because they contained no animals (121 photographs) or because the species could not be identified (212 photographs). And a total of 1555 photographs were taken in 2515 trap days at 117 of the 156 random camera trap locations used during the study (February-May 2013 as the same period with display scrapes). We excluded 17 locations to reduce the zero detection in dataset, following the zero-adjusted approach for denuded assemblages proposed by Clarke

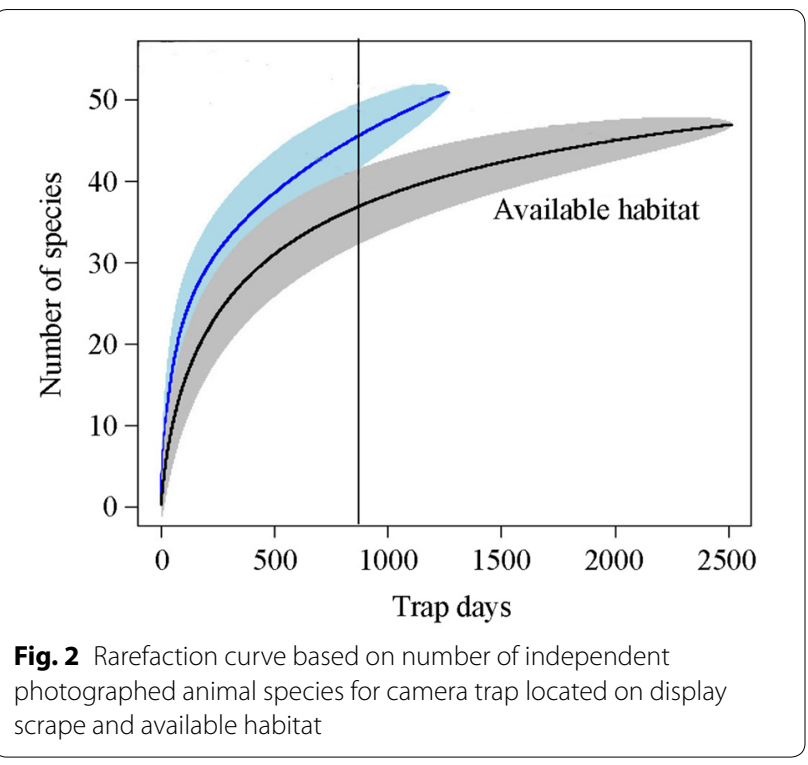

et al. (2006), which gives a mean of 25.15 days/location. There were twenty-eight photographs excluded either because they contained no animal (14 photographs) or because the species could not be identified (14 photographs). Altogether 63 species of animal (32 mammals, 29 birds, 2 reptiles) were photographed at both types of location (Additional file 1: Table S1). Of these animals, 51 species ( 26 mammals, 23 birds, 2 reptiles) were photographed at display scrapes and 48 species $(29$ mammals, 19 birds) at random camera trap locations, of which 36 species (23 mammals, 13 birds) were photographed at both types of location.

The confidence intervals of the rarefaction curve of animal species at display scrapes and random camera trap locations overlapped until the curve reached 800 trapdays which means the number of animal species were not significantly different (Fig. 2). At 800 trap-days, however, the confidence intervals did not overlap and the number of animal species (species richness) recorded at display scrapes (mean species richness $=39.02 \pm 0.28$ ) was higher than at random camera trap locations (mean species richness $=37.51 \pm 0.19 ; F=1.11, p=0.03, \mathrm{df}=1265$, 2514).

The animal assemblages recorded at display scrapes comprised $59.51 \%$ birds, $40.26 \%$ mammals and $0.23 \%$ reptiles. The main bird group detected was Galliformes (82.2\%): Grey Peacock-pheasant (63.64 \pm 10.87$)$, Bar-backed Partridge (Arborophila brunneopectus) (9.35 \pm 3.46$)$, Scaly-breasted Partridge (Arborophila chloropus) (8.02 \pm 3.78$)$, Red Junglefowl (Gallus gallus) $(3.26 \pm 2.08)$ and Kalij Pheasant (Lophura leucomelanos) $(1.29 \pm 0.66)$. The mammal groups present were herbivores $(68.26 \%)$, carnivores $(23.11 \%$ of which $97.70 \%$ were 
small-medium carnivores and $2.30 \%$ large carnivores), omnivores $(7.57 \%)$ and insectivores $(1.06 \%)$.

The animal assemblage recorded at random camera trap locations was $61.13 \%$ mammals and $38.87 \%$ birds. The mammal groups present were herbivores (60.98\%), carnivores (29\%, including small-medium carnivore 95.95\% and large carnivore 4.05\%), and omnivores (10\%). Galliformes were again the bird group represented in most photographs (66.39\%): Grey Peacock-pheasant (5.24 \pm 1.09$)$, Bar-backed partridge $(2.57 \pm 0.61)$, Scaly-breasted Partridge $(0.44 \pm 0.15)$, Red Junglefowl $(0.24 \pm 0.10)$, and Kalij Pheasant $(0.34 \pm 0.12)$ (Additional file 1: Table S1).

The animal composition (species and abundance) at display scrapes was significantly different from the random camera trap locations (ANOSIM $p<0.01$ and $R=0.90$ ) (Fig. 3). There was less variation in the composition of the animal assemblage at display scrapes than at random camera trap locations (Fig. 3): Bray-Curtis dissimilarity between display scrape and random camera trap community was $23 \%$, indicating a high number of shared species between the areas.

\section{Grey Peacock-pheasant and potential predators}

We detected 16 species of predators (carnivores) at both display scrapes and random camera trap locations, of which 14 species were found at display scrapes and 14 species were found at random camera trap locations (Additional file 1: Table S1). We excluded six species of carnivores as potential predators based on our knowledge of predation of Galliformes in SE Asia, including Tiger (Panthera tigris), Leopard (Panthera pardus), Hog Badger (Arctonyx collaris), Crab-eating Mongoose (Herpestes urva), Large-toothed Ferret Badger (Melogale personata), and Asiatic Black Bear (Ursus thibetanus), and then identified ten species that were likely to have an impact on Grey Peacock-pheasant occurrence at display scrapes (Table 4). Because some species were rarely detected we only used the four species that had a mean camera trapping rate (number of photographs $/ 100$ day \pm SE) greater than 0.50 for analysis of their co-occurrence with Grey Peacock-pheasant (display scrape; random camera trap locations): Masked Palm Civet (Paguma larvata) $(5.96 \pm 1.45 ; 2.64 \pm 0.61)$, Large Indian Civet (Viverra zibetha) (2.43 $\pm 1.13 ; 0.85 \pm 0.22$ ), Common Palm Civet (Paradoxurus hermaphroditus) $(1.88 \pm 1.12 ; 0.73 \pm 0.19)$, and Yellow Throated Marten (Martes flavigula) $(0.87 \pm 0.34 ; 0.61 \pm 0.16)$ (Table 4).

Both Masked Palm Civet and Large Indian Civet occurred significantly more at display scrapes than at random camera trap locations (Wilcox-Mann $U$ test, $p<0.001, p<0.01$ respectively), whereas Common Palm Civet and Yellow Throated Marten did not (WilcoxMann $U$ test, $p=0.414, p=0.130$, respectively) (Table 4). When the 10 potential predators were pooled, the mean camera trapping rate was significantly higher at display scrapes than random camera trap locations (Wilcox Mann $U$ test, $p=9.27 \mathrm{E}-04$ ) (Table 4).

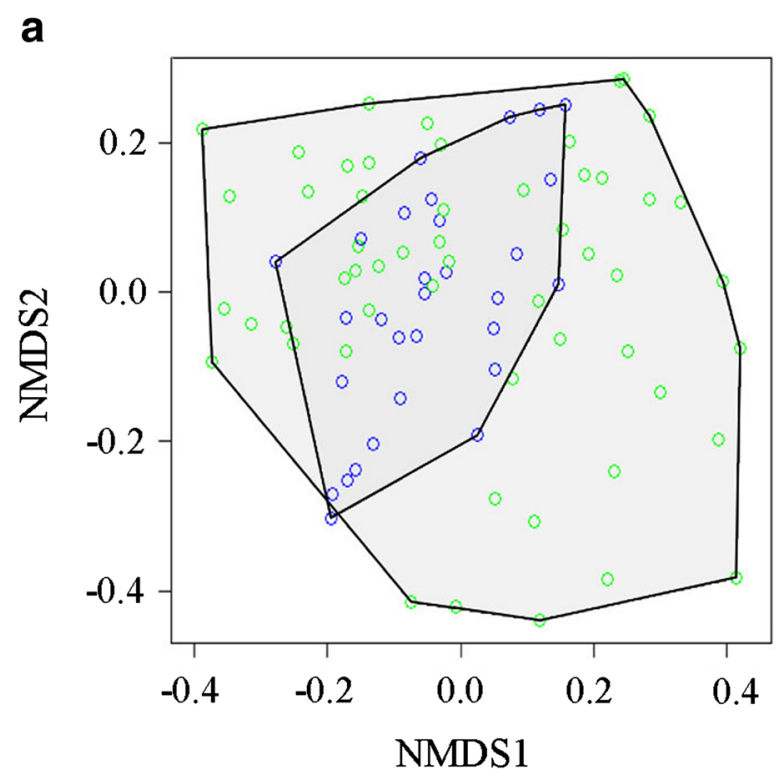

b

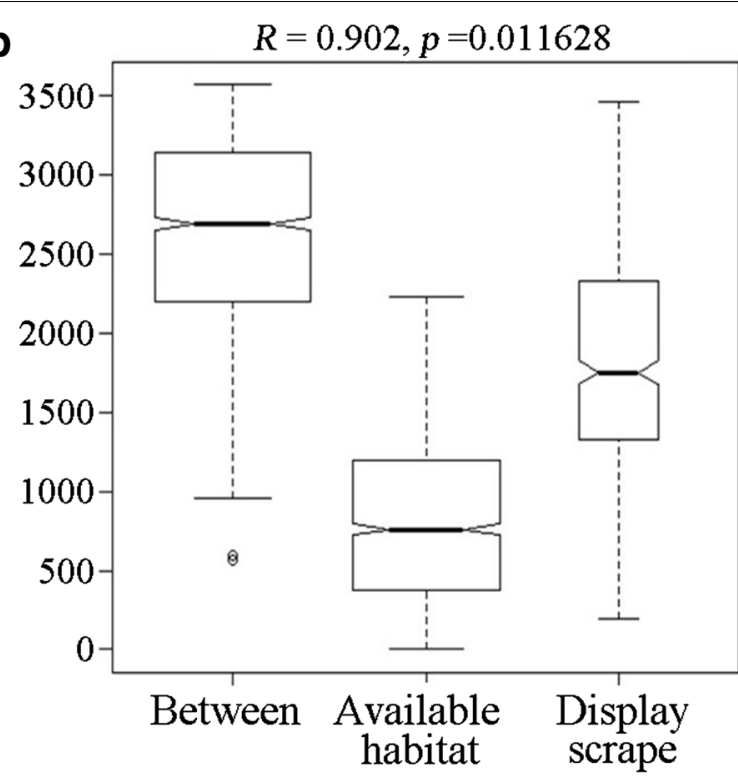

Fig. 3 Ordination graph for a two dimensional scale (NMDS) animal species composition on display scrape and available habitat: blue circle = scrape display, green circle = available habitat by (a); boxplot dissimilarity distance of animal species composition within and between display scrape and available habitat on the Bray-Curtis distance by (b) 
Table 4 Mean and median camera trapping rate (no. of photographs/100 day) of potential predators at display scrapes and available habitat

\begin{tabular}{|c|c|c|c|c|c|c|}
\hline \multirow[t]{2}{*}{ No. } & \multirow[t]{2}{*}{ Species (common name) } & \multicolumn{2}{|c|}{ Display scrape } & \multicolumn{2}{|c|}{ Available habitat } & \multirow[t]{2}{*}{ Mann $U$ test } \\
\hline & & Mean & Median & Mean & Median & \\
\hline 1 & Masked Palm Civet & 5.96 & 3.70 & 2.64 & 0.00 & 0.0007 \\
\hline 2 & Large Indian Civet & 2.43 & 0.00 & 0.85 & 0.00 & 0.046 \\
\hline 3 & Common Palm Civet & 1.88 & 0.00 & 0.73 & 0.00 & 0.409 \\
\hline 4 & Yellow-throated Marten & 0.87 & 0.00 & 0.61 & 0.00 & 0.130 \\
\hline 5 & Marbled Cat & 0.32 & 0.00 & 0.07 & 0.00 & 0.213 \\
\hline 6 & Leopard Cat & 0.02 & 0.00 & 0.20 & 0.00 & 0.527 \\
\hline 7 & Asiatic Golden Cat & 0.20 & 0.00 & 0.07 & 0.00 & 0.213 \\
\hline 8 & Small Indian Civet & 0.06 & 0.00 & 0.00 & 0.00 & 0.075 \\
\hline 9 & Dhole & 0.03 & 0.00 & 0.29 & 0.00 & 0.825 \\
\hline \multirow[t]{2}{*}{10} & Clouded Leopard & 0.00 & 0.00 & 0.08 & 0.00 & 0.436 \\
\hline & Pool predators & $11.98 \pm 2.12$ & 7.41 & $5.81 \pm 0.90$ & 3.33 & 0.0004 \\
\hline
\end{tabular}

Table 5 Top model of 4 highest ranking potential predators and prey co-occurrence (main prey Masked Palm Civet, Large Indian Civet, Common Palm Civet, and Yellow-throated Marten and Grey Peacock-pheasant) at display scrape

\begin{tabular}{lllrl}
\hline Predicting & Top model & Variable & Estimate & SE \\
\hline Psi(occupancy) & PsiA, PsiBA = PsiBa & PsiA & 0.7613 & 0.31 \\
& & PsiBA $=$ PsiBa & -0.1461 & 0.10 \\
P(detection) & $\mathrm{pA} !=\mathrm{rA}$, & $\mathrm{pA}$ & -1.0514 & 0.24 \\
& $\mathrm{pB} !=\mathrm{rBA}=\mathrm{rBa}$ & $\mathrm{rA}$ & -0.3822 & 0.17 \\
& & $\mathrm{pB}$ & -4.2371 & 1.05 \\
& & $\mathrm{rBA}=\mathrm{rBa}$ & 2.2203 & 0.28
\end{tabular}

PsiA probability of occupancy of predators, PsiBA probability of occupancy of Grey Peacock-pheasant when predators are present, PsiBa probability of occupancy of Grey Peacock-pheasant when predators are absent, Pa probability of detection for predators if there are no Grey Peacock-pheasant, $p B$ probability of detection for Grey Peacock-pheasant if there are no predators, $r A$ probability of detection for predators if Grey Peacock-pheasant are present, $r B A$ probability of detection for Grey Peacock-pheasant if predators are present and detected, rBa probability of detection for Grey Peacock-pheasant if predators are present and not detected

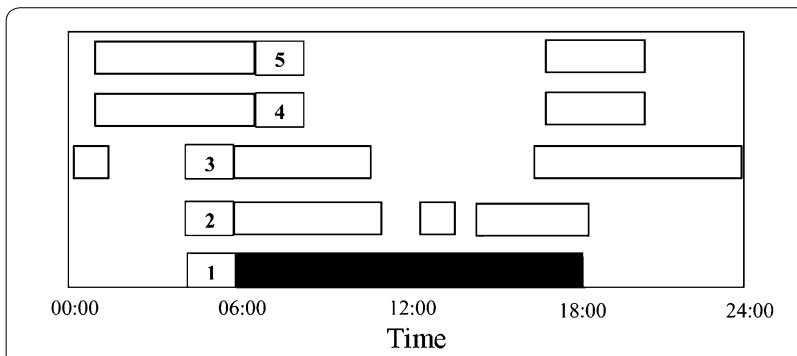

Fig. 4 Activities period of male Grey Peacock-pheasant and four highest ranks of predators at display scrape: (1) Grey

Peacock-pheasant; (2) Yellow-throated Marten; (3) Large Indian Civet; (4) Common Palm Civet; (5) Masked Palm Civet
We evaluated the co-occurrence of the four most commonly photographed potential predators and Grey Peacock-pheasant at 31 display scrapes in terms of both occupancy and detection. The occurrence of Grey Peacock-pheasant at display scrapes did not depend on the occurrence of predators $(\mathrm{PsiBA}=\mathrm{PsiBa})$. However, the detection of Grey Peacock-pheasant did depend on the presence of the potential predators, but not on their detection $(\mathrm{pB}=\mathrm{rBA}=\mathrm{rBa})$, and the detection of predators did depend on the presence of Grey Peacockpheasant $(\mathrm{pA}=\mathrm{rA})($ Table 5). Three of the main predator species were nocturnal mammals (Fig. 4).

\section{Discussions}

Our results show that whilst Grey Peacock-pheasant used most of the microhabitats that were available throughout the study area, they had quite specific requirements for constructing and maintaining display scrapes during the breeding season. These sites presumably provide benefits for males as they seek to attract females (Morris 2003; Kajin et al. 2012) and, for this species, seems likely to be associated with display of the males, as in the closely related Great Argus (Davison 1981) and suggested for the congeneric Malaysian Peacock-pheasant (McGowan 1994).

Display scrapes were located in flat open areas with a low density of insects. Other species of forest Galliformes species are thought to use open understorey where they can detect approaching ground predators, i.e. Sichuan Hill-partridge's (Arborophila rufipectus) (Bo et al. 2009), Siamese Fireback (Lophura diardi) (Sukumal et al. 2017) and Hume's Pheasant (Syrmaticus humiae) (Iamsiri and Gale 2008)). However, we assume that in this case this allows males to show off their eyespots to females during 
courtship behaviour (Davison 1983b). Visibility during male display was also suggested as the main reason why Green Peafowl (Pavo muticus) also predominantly selected open areas during their mating season (Sukumal et al. 2017) as displaying eyespots on its train has an important sexual selection function (Petrie 1994). Moreover, in dense tropical Sundaic forest with relatively steep slopes, flat patches were also selected for the creation of 'dancing grounds' by Great Argus (Davison 1982; Dawrueng et al. 2017) and this species also exhibits eyespots on spread wings during courtship behaviour. Moreover, our model showed that the density of insects was negatively related to display scrape microhabitat selection. We assume that this was because the male in the scrape had already fed on the insects (this assumption was supported by evidence from the video camera traps).

We asked if Grey Peacock-pheasant display scrapes were sited in microhabitats with relatively few potential predators. We found, however, that there were significantly more potential predators at scrapes than random locations. The occurrence of the pheasant was not influenced by these predators, and, therefore, it suggests that they may use tactics other than spatial segregation to avoid these predators. Morris (2003), Ferrari et al. (2009) and Gorini et al. (2012) reported that prey can modify its behaviour in response to predators and shifts in spatial use may also be a reponse to temporal variation in predation risk. However, our detection of predators depended on the presence of Grey Peacock-pheasant, and it is well known that habitat selection of mammalian carnivores may be driven by prey availability (Flaxman and Lou 2009; Keim et al. 2011; Wolff et al. 2015). Diets of omnivorous predators can shift in response to food availability (e.g. Zhou et al. 2008, 2011; Jothish 2011). Therefore, male Grey Peacock-pheasant may be at greater risk of predation during the breeding season as this is in the dry season where there is least fruit available in the environment.

\section{Conclusions}

Grey Peacock-pheasant selects flat and open microhabitats for its display scrapes in dry and hill evergreen forest. There is a higher population of potential predators at these sites than elsewhere in its habitat, but the Grey Peacock-pheasant is able to carry out its courtship at these selected sites as it is diurnal, whereas most of its predators are nocturnal. In subsequent stages, the species may use different tactics to avoid predators, such as using vegetation cover during the nesting and brood rearing phase (Kirol et al. 2012; Latif et al. 2012; Suwanrat et al. 2014). When displaying at scrapes there might be a trade-off between successful mating and predator risk similar to that in male Lesser Prairie-chicken (Tympanuchus pallidicinctus), which selects open areas for leks to display for females in spring, but also suffer from peak mortality at the same time (Hagen et al. 2005; Larsson et al. 2013).

\section{Additional file}

Additional file 1. Table S1. Number of camera trap photographs and mean camera trapping rate (photographs/100 days) $\pm 95 \%$ confidence interval of animal community at display scrape $(n=31)$ and available habitat $(n=100)$ as $1200 \mathrm{~m} \times 1200 \mathrm{~m}$ in Huai Kha Khange Wildlife Sanctuary, Thai Thani, Thailand.

\section{Authors' contributions}

ST designed field study, collected data in field work and performed the analysis. MJG advised on data analysis. PJKM and TS, contributed to the design of the field study. All authors contributed to writing the manuscript. All authors read and approved the final manuscript.

\section{Author details}

${ }^{1}$ Conservation Ecology Program, School of Bioresources and Technology, King Mongkut's University of Technology Thonburi, 49 Soi Thian Thale 25, Bang Khun Thian Chai Thale Road, Tha Kham, Bang Khun Thian, Bangkok 10150, Thailand. ${ }^{2}$ School of Biology, Newcastle University, Ridley Building, Claremont Road, Newcastle upon Tyne NE1 7RU, UK.

\section{Acknowledgements}

We sincerely thank the Department of National Parks Wildlife and Plant Conservation for facilitating our field research in Huai Kha Khaeng Wildlife Sanctuary. Support in the field was provided by S. Daungchantasiri, B. Thongnumchaima, S. Maneerat, A. Simcharoen, P. Rojanadilok, J. Akajak and special thanks go to C. Thongpun, A. Tanisoot, S. Phom Uaeng, T. Khaengkhetkarn, O Jankaew, N. Narod, Na-Noi, Trainee of Science Faculty, Chang Mai University year 2013, Trainee of Forestry Faculty, Kasetsart University year 2013, and all staff of Khao Nang Rum Wildlife Research Station for their assistance in field work. We would like to thank N. Pongpattananurak, S. Vinitpornsawan and D. Ngoprasert for their advice on analysis.

\section{Competing interest}

The authors declare that they have no competing interest.

\section{Availability of data and materials}

The datasets used and/or analyzed during the current study are available from the corresponding author on reasonable request.

\section{Consent for publication}

Not applicable.

\section{Ethics approval and consent to participate}

This study was permitted to do fieldwork in Huai Kha Khaeng Wildlife Sanctuary under the permission from National Parks Wildlife and Plant Conservation Department.

\section{Funding}

This study was supported financially for field work by The Royal Golden Jubilee PhD Program, The National Research Council of Thailand, The Asahi Glass Foundation, and King Mongkut University of Technology Thonburi. Funding from the British Council enabled ST to develop the manuscript with PJKM and MJG at Newcastle University, UK.

Received: 3 October 2017 Accepted: 7 May 2018

Published online: 21 May 2018 


\section{References}

Achard F, Eva HD, Stibig H Jr, Mayaux P, Gallego J, Richards T, Malingreau J-P. Determination of deforestation rates of the world's humid tropica forest. Science. 2002;297:999-1002.

Baker ECS. Game-birds of India, Burma and Ceylon. London: John Bale and Son; 1930.

Bo D, Dowell SD, Garson PJ, He FQ. Habitat utilisation by the threatened Sichuan Partridge Arborophila rufipectus: consequences for managing newly protected areas in southern China. Bird Conserv Int. 2009;19:1-12.

Brown JL, Orians GH. Spacing patterns in miblie animals. Annu Rev Ecol Syst. 1970;1:239-62.

Burnham KP, Anderson DR. Model selection and multimodel inference: a practical information-theoretic approach. 2nd ed. New York: Springer; 2002

Clarke KR, Somerfield PJ, Chapman MG. On resemblance measures for ecological studies, including taxonomic dissimilarities and a zero-adjusted Bray-Curtis coefficient for denuded assemblages. J Exp Mar Biol Ecol. 2006;330:55-80.

Davison GWH. Evolution female choice. Biol J Linn Soc. 1981:15:91-104.

Davison GWH. Sexual displays of the great argus pheasant Argusianus argus. Ethology. 1982;58:185-202.

Davison GWH. Behaviou of Malay peacock pheasant Polyplectron malacense (Aves: Phasianidae). J Zool Soc London. 1983a;201:57-65.

Davison GW. The eyes have it: ocelli in a rainforest pheasant. Anim Behav. 1983b;31:1037-42.

Dawrueng T, Ngoprasert D, Gale GA, Browne S, Savini T. Effect of landscape variables on the long-term decline of Great Argus in the rainforest of Southern Thailand. Bird Conserv Int. 2017;27:282-93.

DeCesare NJ, Hebblewhite M, Bradley M, Hervieux D, Neufeld L, Musiani M. Linking habitat selection and predation risk to spatial variation in survival. J Anim Ecol. 2014;83:343-52.

Donovan TM, Hines J. Exercises in occupancy modeling and estimation. 2007. http://www.uvm.edu/enver/vtcfwru/spreedsheet/occupancy. htm. Accessed 20 Oct 2015.

ESRI. ArcGIS: Release 9.3. Redlands, California: Environmental Systems Research Institute; 2008.

Ferrari MCO, Sih A, Chivers DP. The paradox of risk allocation: a review and prospectus. Anim Behav. 2009;78:579-85.

Flaxman SM, Lou Y. Tracking prey or tracking the prey's resource? Mechanisms of movement and optimal habitat selection by predators. $J$ Theor Biol. 2009;256:187-200.

Fletcher JRJ, Orrock JL, Robertson BA. How the type of antropogenic change alters the consequences of ecological traps. Proc R Soc B. 2012;279:2546-52.

Gillespie GR, Howard S, Stroudd JT, UI-Hassanahe A, Campling M, Lardner B, Scroggie MP, Kusrini M. Responses of tropical forest herpetofauna to moderate anthropogenic disturbance and effects of natural habitat variation in Sulawesi, Indonesia. Biodivers Conserv. 2015;192:161-73.

Gorini L, Linnell JDC, May R, Panzacchi M, Boitani L, Odden M, Nilsen EB. Habitat heterogeneity and mammalian predator-prey interactions. Mamm Rev. 2012;42:55-77.

Hagen CA, Salter GC, Pitman JC, Robel RJ, Applegate RD. Lesser PrairieChicken brood habitat in sand sagebrush: invertebrate biomass and vegetation. Wildl Soc Bull. 2005;30:1080-91.

lamsiri A, Gale GA. Breeding season habitat use by Hume's Pheasant Syrmaticus humiae in the Doi Chiang Dao Wildlife Sanctuary, northern Thailand. Zool Stud. 2008:47:138-45.

IUCN. The IUCN Redlist of Threatened Species Version 2017-1. 2017. http:// www.IUCNredlist.org. Accessed 9 Sept 2017.

Johnsgard P. The Pheasants of the world. Biology and natural history. Washington DC: Smithsonian Institution Press; 1999.

Jothish PS. Diet of the Common Palm Civet Paradoxurus hermaphroditus in a rural habitat in Kerala, India, and its possible role in seed displersal. Small Carniv Conserv. 2011;45:14-7.

Kajin M, Eduardo C, Grelle V. Microhabitat selection when detection is imperfect: the case of an endemic Atlantic forest mammal. Ecol Res. 2012;27:1005-13.

Keim JL, Dewitt PD, Lele SR. Predators choose prey over prey habitats: evidence from a lynx-hare system. Ecol Appl. 2011;21:1011-6.
Kirol CP, Beck JL, Dinkins JB, Conover MR. Microhabitat selection for nesting and brood-rearing by the Greater Sage-grouse in Xeric big sagebrush. Condor. 2012;114:75-89.

Knopff AA, Knopff KH, Boyce MS, Clair CCS. Flexible habitat selection by cougars in response to antropogenic development. Biol Conserv. 2014; 178:136-45

Larsson LC, Pruett CL, Wolfe DH, Patten MA. Fine scale selection of habitat by the lesser prairie chicken. Southwest Nat. 2013;58:135-49.

Latif QS, Heath SK, Rotenberry JT. How avian nest site selection responds to predation risk: testing an 'adaptive peak hypothesis'. J Anim Ecol. 2012;81:127-38

Laurance WF. Reflections on the tropical deforestation crisis. Biol Conserv. 1999;91:109-17.

Mackenzie DI, Bailey LL, Nichos JD. Investigating species co-occurrence patterns when species are detected imperfectly. Anim Ecol. 2004;73:546-55.

Magle SB, Simoni LS, Lehrer EW, Brown JS. Urban predator-prey association: coyote and deer distributions in the Chicago metropolitan area. Urban Ecol. 2014;17:875-91.

Mazerolle MJ. AICcmodavg: Model selection and multimodel inference based on (Q)AIC(c). R package version 2.0-3. 2015. https://cran.r-proje ct.org. Accessed 5 Oct 2015.

McGowan PJK. Display disperson and micro-habitat use by the Malaysian peacock pheasant Polyplectron Malacense in Peninsular Malaysia. Trop Ecol. 1994:10:229-44

Miettinen J, Shi C, Liew SC. Deforestation rates in insular Southeast Asia between 2000 and 2010. Glob Change Biol. 2011;17:2261-70.

Morris DW. Toward an ecological synthesis: a case for habitat selection. Oecologia. 2003;136:1-13.

Mugerwa B, Sheil D, Ssekiranda P, Heist Mv, Ezuma P. A camera trap assessment of terrestrial vertebrates in Bwindi Impenetrable National Park, Uganda. Afr J Ecol. 2012;51:21-31.

National Parks Wildlife and Plant Conservation Department. Huai Kha Khang Wildlife Sanctuary. 2014. http://web3.dnp.go.th/wildlifenew/animC onserveDepView.aspx?depld=17. Accesseded 27 Oct 2014 (in Thai)

Nichols JD, Boulinier T, Hines JE, Pollock KH, Sauer JR. Inference methods for spatial variation in species richness and community composition when not all species are detected. Conserv Biol. 1998:12:1390-8.

Oksanen J, Blanchet FG, Kindt R, Legendre P, Minchin PR, O'Hara RB, Simpson GL, Solymos P, Stevens MHH, Wagner H. Vegan: Community ecology package. R package version 2.3-2. 2015. https://cran.r-proje ct.org. Accessed 20 Nov 2015.

Patthey P, Signorell PN, Rotelli L. Vegetation structure and compositional heterogeneity as a key feature in Alpine black grouse microhabitat selection: conservation management implications. Eur J Wildl Resour. 2012:58:59-70.

Petrie M. Improved growth and survival of offspring of peacocks with more elaborate trains. Nature. 1994;371:598-9.

R Core Team. R: A luaguage and environment for statistical computing. Vienna, Austria: R Foundation for Statistical Computing. 2015. https:// www.cran.r-project.org. Accessed 20 July 2015.

Richmond OMW, Hines JE, Beissinger SR. Two-species occupancy models: a new parameterization applied to co-occurrence of secretive rails. Ecol Appl. 2010;20:2036-46

Robin X, Turck N, Hainard A, Tiberti N, Lisacek F, Sanchez J-C, Müller M. pROC: Display and analysis ROC curve. R package version 1.8. 2015 https://cran.r-project.org. Accessed 20 Oct 2015.

Rovero F, Marshall AR. Camera trapping photographic rate as an index of density in forest ungulates. J Appl Ecol. 2009:46:1011-7.

Sodhi NS, Koh LP, Clements R, Wanger TC, Hill JK, Hamer KC, Clough $Y$, Tscharntke T, Posa MRC, Lee TM. Conserving southeast Asian forest biodiversity in human-modified landscapes. Biol Conserv. 2010;143:2375-84

Sukumal N, Dowell S, Savini T. Micro-habitat selection and population recovery of the Endangered Green Peafowl Pavo muticus in western Thailand: implications for conservation guidance. Bird Conserv Int. 2017;27:414-30

Suwanrat J, Ngoprasert D, Sukumal N, Suwanwaree P, Savini T. Reproductive ecology and nest-site selection of Siamese fireback in lowland forest. Raffles Bull Zool. 2014:62:581-90. 
Wildlife Preservation and Protection Act. Statutes at large, vol 109(Sec. 15), Thailand. 1992 (in Thai).

Wolff PJ, Taylor CA, Heske EJ, Schooley RL. Habitat selection by American mink during summer is related to hotspots of crayfish prey. Wildl Biol. 2015;21:9-17.

Zhou Y, Newman C, Buesching CD, Zalewski A, Kaneko Y, Macdonald DW, Xie Z. Diet of an opportunistically frugivorous carnivore, Martes flavigula, in subtropical forest. J Mamm. 2011;92(3):611-9.
Zhou Y, Zhang J, Slade E, Zhang L, Palomares F, Chen J, Wang X, Zhang S. Dietary shifts in relation to fruit availability among masked plam civet (Paguma larvata) in Central China. J Mamm. 2008;89:435-47.
Ready to submit your research? Choose BMC and benefit from:

- fast, convenient online submission

- thorough peer review by experienced researchers in your field

- rapid publication on acceptance

- support for research data, including large and complex data types

- gold Open Access which fosters wider collaboration and increased citations

- maximum visibility for your research: over $100 \mathrm{M}$ website views per year

At BMC, research is always in progress.

Learn more biomedcentral.com/submissions 